\title{
OPINIÃO
}

\section{Notas Sobre a Política Social}

Igor Zanoni C. Carneiro Leão ${ }^{53}$

Este texto compõe-se de um conjunto de reflexões sobre a política social do Brasil na atualidade. Começamos por resgatar uma distinção fundamental feita por Jean Baudrillard entre contrato e pacto para pensar a forma de funcionar das sociedades liberais modernas.

Como se sabe, o contrato é uma peça central nas economias de mercado, funcionando como uma convenção abstrata entre dois indivíduos que se envolvem dentro de uma relação de troca. Nessa relação, a noção de valor funciona como a ponte que liga dois indivíduos, articulando as sociedades e culturas modernas em seu modo de produção e de circulação de riquezas e de coisas. Essas coisas são mercadorias apreciáveis e a transcendência do valor que se traduzem numa transcendência também do poder baseado na manipulação dos valores mercantis.

O pacto, por seu lado, é próprio de sociedades em que a troca se dá no interior de uma relação dual e cúmplice desligada de uma relação de valor e de mercado. Nessas sociedades, a troca se dá entre indivíduos que não podem ser indiferentemente substituídos uns pelos outros, não há como referencial um equivalente geral comum, a troca pode ser mais bem pensada, como pensa a antropologia, como uma troca simbólica onde há uma circulação de bens que exclui a idéia de valor e o conceito de mercado. As trocas são "ritualizadas" e a vida material é concebida como um ciclo reversível, que põe em movimento tudo o que pertence ao mundo e à comunidade. Nesse sentido não há um comércio racional e o conceito de valor não se coloca. Ao contrário, não há valor, há diretamente a comunidade, circular e reversível, inserida num circuito material e simbólico.

Ora, nas sociedades mercantis o contrato é o veículo por excelência da troca e das relações de sociabilidade não apenas mercantis como inclusive morais. Essas sociedades estabelecem-se de pleno direito no ocidente, a partir do final do século XVIII, com a "dupla revolução" que é como Hobsbawm denomina o paralelismo entre a revolução industrial inglesa e a revolução francesa. Essas sociedades nascem de forma utópica e radical como sociedades de mercado capazes de funcionar autonomamente em relação ao Estado, na medida em que haja liberdade de trabalho e liberdade de comércio. Daí a crítica e o combate

\footnotetext{
${ }^{53}$ Doutor em economia pela Unicamp e Professor da UFPR. Endereço eletrônico: igorza@bol.com.br.
} 
ao mercantilismo e às políticas de assistência ao trabalho do Antigo Regime. Essa ideologia radical foi bem resenhada por Robert Castel mais recentemente, mas já havia sido apontada, por exemplo, com a história dos argumentos políticos favoráveis ao capitalismo, feita por Albert Hirschman. Essa utopia radical reveste o pensamento de Adam Smith.

Como lembra bem Castel, o liberalismo que marca a sociedade industrial é conquistador, iconoclasta e revolucionário, ao procurar eliminar os obstáculos ao advento da liberdade de mercado nas sociedades modernas. Entretanto, ao longo do século XIX sua posição muda, tornando-se restaurador da ordem social, enfrentando não mais um excesso de regulações pesadas e arcaicas, mas os riscos de desintegração social que aparecem com o pauperismo de massa inerente a essas sociedades em seus primórdios. A busca de preservar a paz social origina vertentes diversas de filantropia social sem romper com o liberalismo.

Vai haver por um lado, um liberalismo desconfiado de qualquer intervenção capaz de influenciar, por menor que seja, as leis do mercado. Para estes, entre os quais se inclui Thomas Malthus, a pobreza é um mal necessário e até útil que deve ser tratado através de práticas caritativas tradicionais. Por outro lado, surgem reformadores sociais que procuram elaborar a questão social como a reabilitação da pobreza das classes trabalhadoras. As estratégias utilizadas para isso são: a assistência aos indigentes através de técnicas de trabalho social, o desenvolvimento de instituições de poupança e previdência voluntária colocando no horizonte uma segurança social e a instituição da proteção patronal.

Essa filantropia consiste em uma construção de uma política social sem Estado, de essência moral, baseada em última análise na adesão do povo aos valores que the são impostos. O mundo operário, entretanto, termina por rejeitar esses valores da caridade e do paternalismo patronal, à medida que elabora seus próprios modos de organização. Essa situação só vai ser rompida quando o Estado passa a ser um parceiro implicado no jogo social dotando-se de novas funções para controlar o antagonismo entre os partidários da moralização do povo e os partidários da luta de classe. A política social deixa um espaço puramente ético de moral pública regulamentando relações sociais sem sanção jurídica e passa a ser política propriamente dita. Desenham-se assim alternativas de visões diante do social desde um liberalismo rude, a filantropia, o solidarismo chegando a concepções socialistas.

Utilizando essas idéias para pensar o Brasil, podemos lembrar inicialmente a importância nos anos 80 do conceito de pacto social como uma senha de aglutinação contra a economia política do regime militar. Militava-se nesse período contra o crescimento econômico per se, contra o que Furtado chamava o mito do desenvolvimento econômico e a 
dependência cultural. De autores como este último, retomava-se o conceito de economia nacional nucleada em valores como a soberania política, a igualdade social, a industrialização sustentada e um "Ethos" de uma cultura comum, capaz de articular os indivíduos de forma solidária. Evidentemente, exigia-se para isso um outro Estado, uma Nova República. Um dos pontos centrais é indicado em Pequena Introdução ao Desenvolvimento:

"A rigor, a idéia de desenvolvimento possui pelo menos três dimensões: a do incremento, da eficácia do sistema social de produção, a da satisfação de necessidades elementares da população e a da consecução de objetivos a que almejam grupos dominantes de uma sociedade e que competem na utilização de recursos escassos. A terceira dimensão é, certamente a mais ambígua, pois aquilo a que aspira um grupo social pode parecer simples desperdício de recursos a outros. Daí que essa terceira dimensão somente chegue a ser percebida como tal como parte de um discurso ideológico. Assim a concepção de desenvolvimento de uma sociedade não é alheia a sua estrutura social, e tampouco a formulação de uma política de desenvolvimento e sua implantação são concebíveis sem preparação ideológica."

Essa citação, feita por Plínio de Arruda Sampaio Jr. em artigo por ocasião da morte de Furtado, significa a crítica severa deste último ao funcionamento de uma economia como algo independente do corpo social e crítica à mistificação do progresso técnico e da racionalização do status quo. Ao mesmo tempo, ela se liga à crítica de uma situação de subdesenvolvimento responsável por um padrão de acumulação que cristaliza uma sociedade marcada pela dependência externa, pela segregação social e pela heterogeneidade estrutural das forças produtivas. Nem por outro motivo Furtado foi chamado como padroeiro das forças oposicionistas ao regime militar.

Nesse contexto de redemocratização do país, a política social avança, sobretudo na Constituição de 1988, que amplia direitos principalmente no campo trabalhista e na seguridade. Por exemplo, a redução da jornada de trabalho de 48 para 44 horas; o direito de greve, a liberdade sindical e o seguro desemprego para trabalhadores urbanos e rurais passam a ser garantidos e a seguridade - incluindo previdência, saúde e assistência social - passa a ter acesso universalizado e descentralizado, facilitando-se seu controle pela sociedade. Paradoxalmente, a partir dos anos 90 percebe-se segundo analistas como Eduardo Fagnani um desmonte das políticas públicas, a pulverização das ações e a fragmentação de direitos sociais tornando-se mais seletiva a proteção social com recursos mais limitados e 
contingenciados. Esta situação permanece segundo pensamos até hoje e é importante saber o por quê.

Os aspectos mais importantes são as mudanças na economia mundial, no que tange ao Brasil entre outros países, desde os anos 90, que alteraram a forma de gestão da política macroeconômica e da política fiscal. Desde esse período a maior integração mundial amplia o movimento de capitais e incorpora países como o Brasil ao circuito da valorização do capital financeiro internacional. Isto põe fim ao isolamento das políticas domésticas e implica em importantes mudanças na estrutura institucional do país e na gestão da política macroeconômica, que passa a ser vista como um meio de assegurar a estabilidade e o retorno dos investimentos financeiros, defendendo-se um regime de política econômica com um horizonte de longo prazo.

Como aponta Lopreato (2004), entre outros analistas, a partir de 1999 a política fiscal, como uma das peças centrais da política macroeconômica, passa a ter a obrigação de garantir a sustentabilidade da dívida externa, independentemente dos valores de juros e de câmbio, o que implica num esforço fiscal e na centralidade da política fiscal para preservar a solvência da dívida. Num país com uma elevada dívida pública como o Brasil, gerou-se uma preocupação com uma âncora fiscal suficientemente ampla que deixa de ter papel de suporte à demanda agregada. Nesse contexto é difícil sustentar a compatibilidade entre crescimento econômico, altas taxas de juros reais e o superávit primário requerido, especialmente no atual momento econômico de incerteza no cenário internacional e alta nas taxas de juros. Estas últimas exigem um esforço fiscal crescente e o espaço orçamentário se reduz.

Nesse quadro, crescem os gastos com juros e amortização líquida da dívida e se entravam as despesas de caráter social como as contas da previdência e os gastos com pessoal. A situação da previdência indica um crescimento dos gastos e do déficit nos últimos anos ligados ao envelhecimento da população, ao alto desemprego e ao tamanho do mercado informal. O crescimento da economia a taxas mais elevadas contribuiria para solucionar o dilema da previdência, mas as altas taxas de juros impedem essa expansão, além de reduzir o espaço para gastos de custeio e de investimentos. Esta situação tende a piorar com os sinais negativos da economia mundial, da taxa de crescimento interno e da carga de juros sobre a dívida pública.

Os gastos com políticas sociais abrangem as áreas, pela ordem de importância, de saúde, educação, desenvolvimento social e combate à fome, previdência social, trabalho e 
emprego, cultura e esporte, mas esses gastos têm sido contingenciados e cortados, embora menos que outros gastos, exceto juros e amortização líquida da dívida.

É importante notar aí como a situação do mercado de trabalho é crucial para as famílias pobres. Sabe-se, por exemplo, que a taxa de desemprego nessas famílias é duas vezes maior que a média nacional e que em geral elas estão no setor informal sem carteira assinada e sem contribuir para previdência social. Se pensarmos no principal programa social do governo voltado para essas famílias, o Programa Fome Zero, é possível perceber que as condições de pobreza decorrem de uma vulnerabilidade social ligada ao trabalho, bem como a falta de habitação, água e saneamento, educação e saúde. Essa população atinge 46 milhões de pessoas, segundo o Programa, o que mostra a importância de articulação dos programas sociais e a enorme vulnerabilidade social presente no Brasil. Essa vulnerabilidade está ligada às carências criadas pela insuficiência de renda, pelo não atendimento das necessidades básicas de caráter individual ou coletivo e pela falta de capacitação para se inserir adequadamente na sociedade levando-se em conta seu grau de desenvolvimento.

Nesse sentido, as próprias condições de reprodução adequada desse nível de desenvolvimento estão comprometidas. Retomem-se aqui, em relação à política econômica, as críticas de Furtado ao economicismo do regime militar e a sensação de volta a um regime liberal de condução da questão social. Na realidade o espaço de solidariedade da sociedade brasileira presente nas políticas públicas está se esgarçando e um dos seus indicadores é a incapacidade da política social dar conta da insegurança social.

Essas observações são preocupantes quando se sabe que o objetivo do Programa Fome Zero não era o assistencialismo mas a inclusão social através da universalização dos direitos de cidadania começando por ações estruturantes ligadas aos direitos sociais básicos como acesso a alimentação, saúde, educação, previdência e proteção de emprego, atingindo 11,4 milhões de famílias, entre as quais as beneficiadas pelo Programa Bolsa Família, que a partir de 2003 unificou os programas de transferência de renda, que atinge 5 milhões de famílias. A meta é incluir no Programa Bolsa Família toda a população alvo do Programa Fome Zero.

Para o Ministro do Desenvolvimento Social e Combate à Fome Patrus Ananias, esses objetivos significariam um deslizamento do social em eixo do desenvolvimento enfrentando os fatores estruturais que determinam os padrões de apropriação e distribuição da renda e da riqueza. Ele reconhece que o crescimento acentuado da dívida pública limitou drasticamente a capacidade do Estado em responder às demandas da sociedade e que hoje o financiamento 
das políticas sociais exige uma profunda alteração no perfil do gasto público, voltado primordialmente para transferências de terceiro e pagamento de cargos financeiros da dívida externa e interna. De fato, em 2004 os gastos com juros e amortização líquida da dívida superaram 150 bilhões de reais ou 8,67\% do PIB, o que relativiza bastante a crítica daqueles que vêem o problema das contas públicas nos gastos sociais.

Fica claro, portanto, uma conjuntura econômica instável e em deterioração, uma insatisfação social num momento politicamente delicado pelas eleições do próximo ano e a importância de decisões fiscais e do conjunto da política pública, que têm como contrapartida uma larga vulnerabilidade social. Na verdade, os objetivos do Programa Fome Zero deveriam realmente ser estendidos ao conjunto dos objetivos de governo, mas isso parece utópico.

Tão utópico, por exemplo, como usar o BNDES como um banco com uma real dimensão social. Sabe-se que entre 2000 e 2004, os recursos direcionados para a área social tiveram uma queda percentual importante, especialmente porque sua participação no total dos embolsos já era muito baixa. Em 2004 esse índice era de 3,82\% e entre janeiro e julho de 2005 os desembolsos foram apenas 2,2\% do total desembolsado, totalizando reais 541,4 milhões. Se pensarmos que um conjunto de organizações da sociedade vem trabalhando com questões como superação das desigualdades étnicas e de gênero, valorização de culturas locais e combate aos danos ao meio ambiente gerados pelo crescimento econômico, seria importante que elas fossem ouvidas pelo banco, uma vez que é obscuro quais foram os projetos financiados sob a rubrica "social".

Voltando ao início do texto, à guisa de conclusão talvez se possa dizer que este é o momento de repensar contratos e refazer pactos. Entretanto, talvez não haja poder de Estado para tanto, além de a pobreza brasileira não ter suficiente poder político.

\section{Referências Bibliográficas}

Baudrillard, J. (2001). Senhas, Rio de Janeiro: DIFEL.

Castel, R. (1998)As metamorfoses da questão social: uma crônica do salário, Petrópolis, RJ: Vozes.

Hirschman, A.O (1079). As paixões e os interesses: argumentos políticos para o capitalismo antes do seu triunfo, Rio de Janeiro: Paz e Terra.

Lopreato, F.L (2004). Finanças públicas: a marcha continua, in Política econômica em foco, n 5 - nov. 2004/abr. 2005, Instituto de Economia, Unicamp; 
Sampaio Jr., P.A. (?????). Furtado: um economista a serviço da nação, texto para discussão, Instituto de Economia, Unicamp.

Dedecca, C.S. e Barbieri, C.V. (2005). Fome Zero e pilotos para a política social, Cesit, Instituto de Economia, Unicamp.

Ananias, P. e Frei Betto (2004). Fome Zero, artigo originalmente publicado no jornal Diário de São Paulo.

Boletim de acompanhamento social do BNDES, www.ibase.br. 
